\title{
Studies on the Polymerization of Acrolein Oxime. II. Thermal Polymerization
}

\author{
Seizo MAsuda and Tadatoshi OTA \\ Department of Applied Chemistry, Faculty of Engineering, \\ Tokushima University, Tokushima 770, Japan.
}

(Received December 22, 1976)

\begin{abstract}
The same values of the monomer reactivity ratios are experimentally obtained for both the thermal and catalyzed copolymerizations of acrolein oxime with vinyl compounds such as acrylonitrile, methyl methacrylate, and styrene, the catalyst being $n$-butyllithium. On the basis of these data, it is proposed that thermal polymerization of the oxime proceeds by an anionic mechanism, and that the initiating species is an anion, $\mathrm{CH}_{2}=\mathrm{CH}-\mathrm{CH}=\mathrm{N}-\mathrm{O} \ominus$, arising from the dissociation of the molecular aggregates of the oxime. In the thermal polymerization at $60^{\circ} \mathrm{C}$, the product is a white, hygroscopic and powdery polymer having a low molecular weight of $1000-$ 2000. The polymer consists of two or more types of structural units and this may be explained in terms of the resonance phenomenon and the migration of a proton at the growing chain end.
\end{abstract}

KEY WORDS Acrolein Oxime / Thermal Polymerization / Thermal Copolymerization / Anionic Mechanism / Structures of Polymer / Syn-Anti Isomerization /

Numerous papers have described the thermal polymerization of vinyl compounds as a reaction which generally proceeds by a radical mechanism. In our previous paper, ${ }^{1}$ however, we suggested that a nonradical mechanism is operative in the case of acrolein oxime (AOM). This suggestion is based mainly on the following two facts: (1) Neither the presence nor the absence of azobisisobutyronitrile (AIBN) or $p$ benzoquinone affects the velocity of the polymerization of AOM. (2) AOM is an efficient inhibitor of radical polymerizations. In order to elucidate further the mechanism of the thermal polymerization, a comparative study of the thermal and the catalyzed copolymerizations of AOM with acrylonitrile (AN), methyl methacrylate (MMA), or styrene (ST) was undertaken.

\section{EXPERIMENTAL}

\section{Materials}

AOM was prepared by the same method as described in the previous paper ${ }^{2}$; bp $44^{\circ} \mathrm{C}$ $(14 \mathrm{~mm})$, and $O$-methyl acrolein oxime (MAOM) by the method of Ioffe and Zelenin ${ }^{3}$; bp 70$72^{\circ} \mathrm{C} / 760 \mathrm{mmHg}$. AN, MMA, and ST were purified by the ordinary methods and distilled prior to use.

\section{Polymerization Procedure}

Thermal polymerization and thermal copolymerization were carried out at $60^{\circ} \mathrm{C}$ in sealed tubes. The copolymerization by the use of initiators was carried out at $0^{\circ} \mathrm{C}$ under agitation in a glass tube provided with a rubber plug through which a solution of $n$-butyllithium in $n$-hexane or concentrated hydrochloric acid was injected. Reactor tubes were opened after a designated time; those contents were brought together with large amount of ether so that the polymers precipitated as a result. The polymers were washed with appropriate solvents, dried under reduced pressure, and weighed.

\section{Analyses of Acrolein Oxime Polymer (PAOM) and Copolymers}

The composition of resulting copolymers was determined by elementary analysis, and the monomer reactivity ratio was estimated by the 


\section{S. MASUdA and T. OTA}

Fineman and Ross method. ${ }^{4}$ The molecular weights of PAOM and copolymers were determined using dimethylformamide (DMF) as the solvent at $70^{\circ} \mathrm{C}$ by a vapor pressure osmometer (Hitachi Perkin-Elmer, model 115). The oxime group in PAOM was reduced to the primary amine with hydrogen in the presence of a Raney Nickel catalyst, ${ }^{5}$ and then the amount of the amine was determined by the Van Slyke method. ${ }^{6}$ The content of carboncarbon double bond was calculated by determining the iodine value. ${ }^{7}$

PAOM was hydrolyzed in the following way: $0.71 \mathrm{~g}$ PAOM was dissolved in $10 \mathrm{~m} l$ of a $1: 1$ methanol-water mixture containing 5-\% potassium hydroxide, then heated at $60^{\circ} \mathrm{C}$ for $3 \mathrm{hr}$. After neutralization of the solution, the resulting potassium chloride was removed, the hydrolysis product was identified by gas chromatography under the same conditions as described above. ${ }^{2}$ The ratio of the syn and anti forms in AOM was also measured by gas chromatography.

The NMR spectrum was obtained with a JOEL PS-100 spectrometer $(100 \mathrm{MHz})$ at $21^{\circ} \mathrm{C}$ using deuterated dimethyl sulfoxide (DMSO- $d_{6}$ ) as the solvent and tetramethylsilane (TMS) as the internal standard. The polymer concentration was approximately $7.6 \%$ (wt/vol).

\section{RESULTS AND DISCUSSION}

Copolymerization of AOM with Vinyl Compounds AOM thermally reacted with anyone of the substances, AN, MMA, and ST, at $60^{\circ} \mathrm{C}$. This substance was in every case insoluble in benzene, but easily soluble in both acidic and basic aqueous solutions. This solubility behavior indicates that the product is, in all cases, not a mixture of polymers arising from the independent polymerizations of AOM and some other starting substance. Obviously, it is a copolymer; this conclusion is also supported by the infrared spectroscopic data on these products. The spectra exhibit a nitrile peak at 2240, a carbonyl peak at 1735 and phenyl peaks at 765 and $710 \mathrm{~cm}^{-1}$ for the systems of AOM-AN, AOM-MMA, and AOM-ST, respectively.

Figures 1-3 show monomer-copolymer composition curves for the present three systems. In every system the curve for the thermal co- polymerization almost completely coincides with that for the anionic copolymerization in the presence of $n$-butyllithium. The addition of AIBN never once affected the velocities of the thermal copolymerizations as well as the compositions of the resulting substances. However, $\mathrm{AOM}$ is found to be an efficient inhibitor of

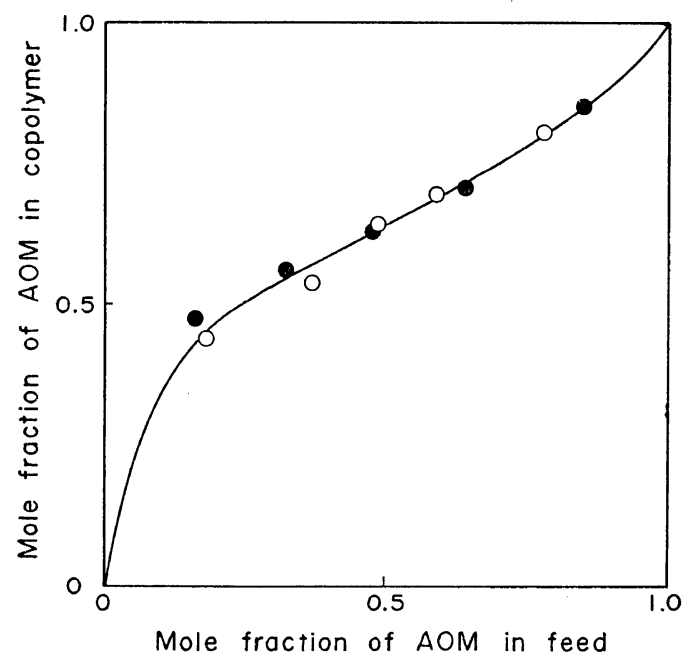

Figure 1. Copolymerization diagram for $\mathrm{AOM}-$ AN system: $\bigcirc$, thermal copolymerization at $60^{\circ} \mathrm{C}$; $\boldsymbol{O}$, anionic copolymerization in the presence of BuLi at $0^{\circ} \mathrm{C}$.

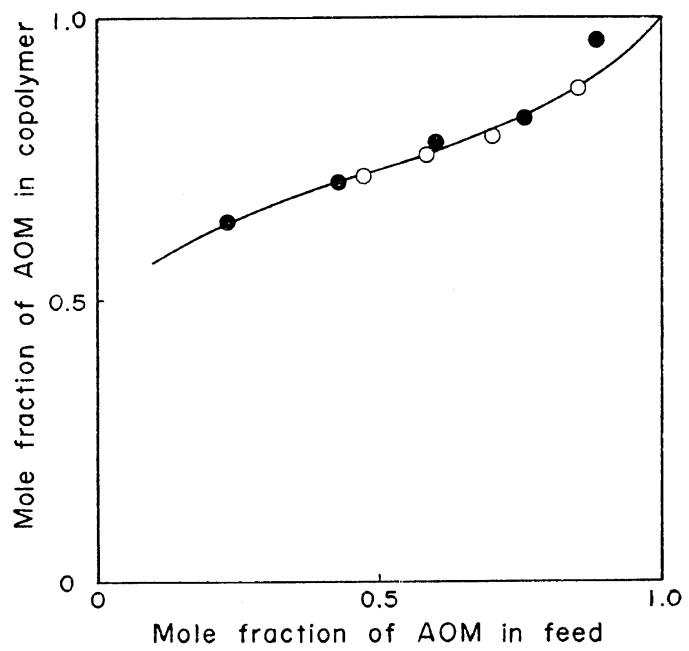

Figure 2. Copolymerization diagram for AOMMMA system: $O$, thermal copolymerization at $60^{\circ} \mathrm{C}$; anionic copolymerization in the presence of $\mathrm{BuLi}$ at $0^{\circ} \mathrm{C}$. 


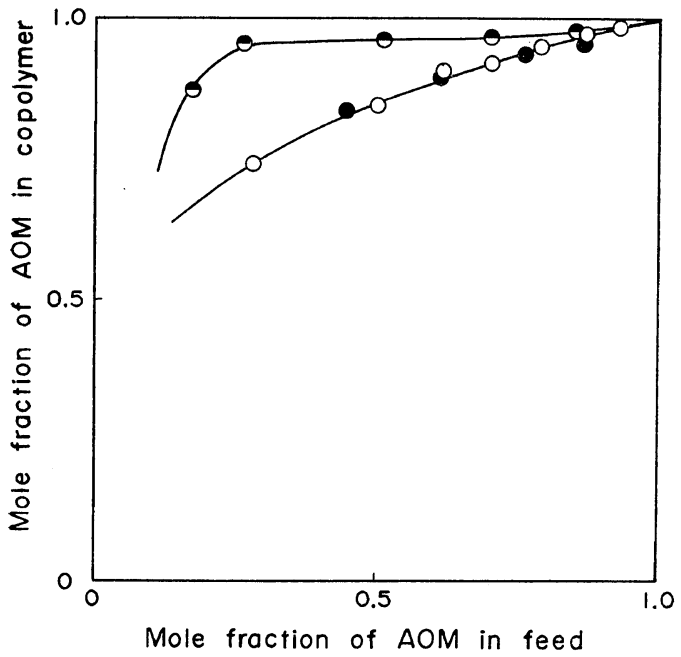

Figure 3. Copolymerization diagram for AOMST system: $\bigcirc$, thermal copolymerization at $60^{\circ} \mathrm{C}$; , anionic copolymerization in the presence of $\mathrm{BuLi}$ at $0^{\circ} \mathrm{C}$; $\Theta$, cationic copolymerization in the presence of $\mathrm{HCl}$ at $0^{\circ} \mathrm{C}$.

Table I. Monomer reactivity ratios in copolymerizations of AOM with reference monomers

\begin{tabular}{ccccc}
\hline $\mathrm{M}_{1}$ & $\mathrm{M}_{2}$ & Initiator & $r_{1}$ & $r_{2}$ \\
\hline \multirow{2}{*}{ AOM } & \multirow{2}{*}{ AN } & None & 1.0 & 0.1 \\
& & BuLi & 1.0 & 0.1 \\
AOM & \multirow{2}{*}{ MMA } & None & 1.4 & 0 \\
& & BuLi & 1.4 & 0 \\
AOM & \multirow{2}{*}{ ST } & None & 9.8 & 0 \\
& & BuLi & 9.8 & 0 \\
& & HCl & 30 & 0.01 \\
\hline
\end{tabular}

radical polymerizations as described in our previous paper. ${ }^{1}$ These facts indicate that an anionic mechanism is operative in the thermal polymerization of AOM.

Monomer reactivity ratios measured in these copolymerization systems are summarized in Table I, which obviously indicates that in all cases the active ends of the growing chains react more readily with $\mathrm{AOM}$ than with any of the comonomers. The molecular weights of the resultant copolymers were all about 1000 , almost the same as or lower than that of the PAOM formed by the thermal polymerization of AOM.
MAOM has a structure arising from substitution of a methyl group for the hydrogen atom of the hydroxyl group in AOM, and does not polymerize by itself, but rather copolymerizes with AOM on heating. The infrared spectrum of the resulting polymer shows absorption peaks at 1700 and $1610 \mathrm{~cm}^{-1}$; the former peak is assigned to the $\mathrm{C}=\mathrm{N}$ streching vibration in the MAOM structural unit, and the latter to that in the AOM unit. Thus the hydrogen atom of the hydroxyl group of AOM seems to play an important role in the thermal polymerization of AOM.

\section{Syn-Anti Isomerization of AOM}

$\mathrm{AOM}$ is ordinarily an equilibrium mixture of two isomers, about $17 \%$ of the syn and $83 \%$ of the anti forms, which can be separated into their pure states by gas chromatographic means. ${ }^{2}$ The content of anti form in the unpolymerized portion of the AOM that had been enriched in the syn form component varied with time during the thermal polymerization in an atomosphere of nitrogen as shown in Figure 4. The isomerization seemed to attain equilibrium eventually when the anti form content became about $17 \%$. This isomerization, as is often the case with oximes, seems to take place during the liberation of the proton from the hydroxyl group. ${ }^{8}$

$$
\mathrm{R}-\mathrm{CH}=\mathrm{N}-\mathrm{OH} \rightleftarrows \mathrm{R}-\mathrm{C} \mathrm{CH}-\mathrm{N}=\mathrm{O}
$$

Also, any oxime molecules can associate with each other to form cyclic aggregates by hydrogen bonds of the two types, $\mathrm{O}-\mathrm{H}--\mathrm{N}$ and $\mathrm{O}-\mathrm{H}--\mathrm{O}{ }^{9} \quad$ The infrared spectrum of AOM shows an $\mathrm{OH}$ peak at 3250 and a $\mathrm{C}=\mathrm{N}$ peak at $1610 \mathrm{~cm}^{-1}$, indicating the shifts of frequencies from those which would be measured when AOM is expected to be in a monomeric form at a very dilute concentration. The apparent molecular weight of AOM in benzene at a molality of 0.86 was cryoscopically determined to be 160, which gives an estimate of 2.3 for the aggregation factor, i.e., the number of molecules per an aggregate.

Thus, those anions which initiate the thermal polymerization of AOM are probably produced by dissociation of the aggregates: 


$$
\begin{array}{cc}
(\mathrm{AOM})_{2-3} \rightleftarrows \mathrm{CH}_{2}=\mathrm{CH}-\mathrm{CH}=\mathrm{N}-\mathrm{O} \ominus+\mathrm{CH}_{2}=\mathrm{CH}-\mathrm{CH}=\stackrel{\oplus}{\mathrm{N}} \mathrm{H}-\mathrm{OH}+(\mathrm{AOM})_{0-1} \\
\left(\text { or } \mathrm{CH}_{2}=\mathrm{CH}-\mathrm{CH}=\mathrm{N}-\stackrel{\oplus}{\mathrm{O}} \mathrm{H}_{2}\right) \\
{[\mathrm{AOM} \ominus]} & {\left[\mathrm{AOM}^{\oplus}\right]}
\end{array}
$$

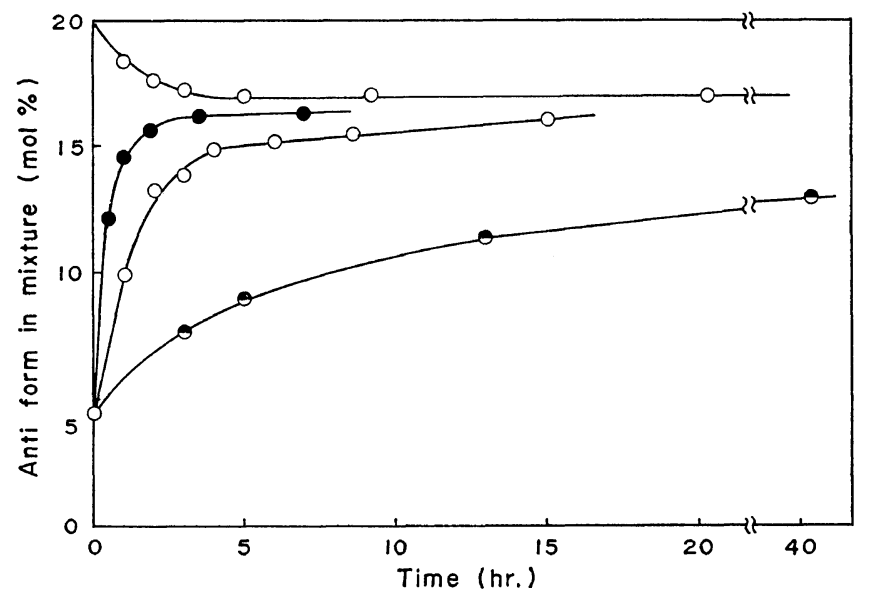

Figure 4. Syn-anti isomerization of $\mathrm{AOM}: \theta, 45^{\circ} \mathrm{C} ; \bigcirc, 60^{\circ} \mathrm{C} ; \mathrm{O}, 70^{\circ} \mathrm{C}$.

where $(\mathrm{AOM})_{1}$ and $(\mathrm{AOM})_{2-3}$ represent the free $\mathrm{AOM}$ and the AOM aggregate with the aggregation factor of 2 or 3 , respectively. The AOM anion has three resonance structures formulated as

$$
\begin{aligned}
& \mathrm{CH}_{2}=\mathrm{CH}-\mathrm{CH}=\mathrm{N}-\mathrm{O} \ominus \leftarrow \mathrm{CH}_{2}=\mathrm{CH}-\stackrel{\ominus}{\mathrm{C}} \mathrm{H}-\mathrm{N}=\mathrm{O} \\
& \text { [I] } \\
& \text { [II] } \\
& \longleftrightarrow \stackrel{\ominus}{\mathrm{C}} \mathrm{H}_{2}-\mathrm{CH}=\mathrm{CH}-\mathrm{N}=\mathrm{O}
\end{aligned}
$$$$
\text { [III] }
$$

Isomerization between the syn and anti forms of AOM seems to proceed via structures [II] and [III], because the free rotation about the carbon-nitrogen bond is favorable for only these two structures.

AOM can easily polymerize in the presence of either an anionic or cationic catalyst. Therefore, both of the anion and cation, concurrently arising from the ionic dissociation of the AOM aggregates, can be the initiator of the thermal polymerization of AOM. When $n$-butyllithium was added to AOM at a temperature below $0^{\circ} \mathrm{C}$, the evolution of butane was clearly detected by gas chromatography, which apparently is indication of the occurrence of the following reaction.

$$
\begin{aligned}
& \mathrm{CH}_{2}=\mathrm{CH}-\mathrm{CH}=\mathrm{N}-\mathrm{OH}+n-\mathrm{BuLi} \rightarrow \\
& \mathrm{CH}_{2}=\mathrm{CH}-\mathrm{CH}=\mathrm{N}-\mathrm{O} \ominus \mathrm{Li} \oplus+\text { butane }
\end{aligned}
$$

Therefore, the anion, $\mathrm{CH}_{2}=\mathrm{CH}-\mathrm{CH}=\mathrm{N}-\mathrm{O} \ominus$, also seems to be an initiator in addition to the butyl anion for the anionic polymerization in the presence of $n$-butyllithium. Considering this conclusion together with the above-described data on the copolymerization, we can reasonably assume that the AOM anion is the initiator in the thermal polymerization of AOM.

The AOM cation would also take part in the termination process

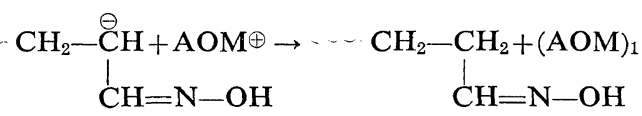

and the chain transfer would occur only between the growing chain end and AOM aggregates.

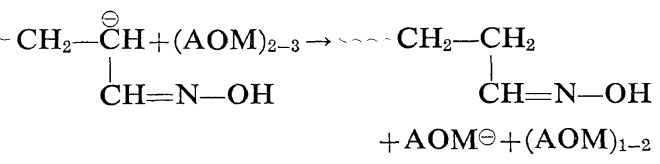

Chemical Structure of PAOM

The initial rate of the thermal, bulk polymerization of $\mathrm{AOM}$ at $60^{\circ} \mathrm{C}$ was $2.73 \times 10^{-4}$ $\mathrm{mol} / \mathrm{lsec}$. The resulting polymer is a white, hygroscopic powder, and soluble in both acidic and basic aqueous solutions and insoluble in most organic solvents except for DMF. On 
being allowed to stand in air, the polymer gradually becomes insoluble. The numberaverage molecular weight value is within the range of $1000-2000$.

When AOM is added to a growing chain, there are five possible paths, respectively, which lead to the structures of chain unit: (A) 1,2addition, (B) 3,4-addition, (C) 1,4-addition, (D) and (E) hydrogen transfer. The last two were suggested by Breslow, et al. ${ }^{10}$

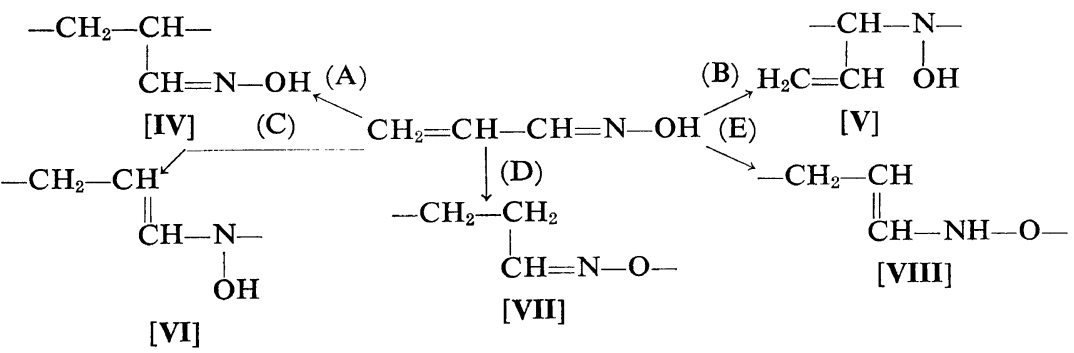

A sample PAOM $\left(M_{W}, 2100\right)$ contained $42 \%$ of the structural units having a carbon-carbon double bond per unit, $46 \%$ of those having a pendant oxime per unit, and $12 \%$ of unknown structural units.

If the polymerization proceeds by path (A), the pendant oxime remains unchanged, and hence the content of [IV] is $46 \%$ in the resultant PAOM. Paths (B), (C), and (E) can yield respectively the carbon-carbon double bond units. But the path (B) is compared with path (A), unlikely to occur owing to the instability of the resulting anion and the steric

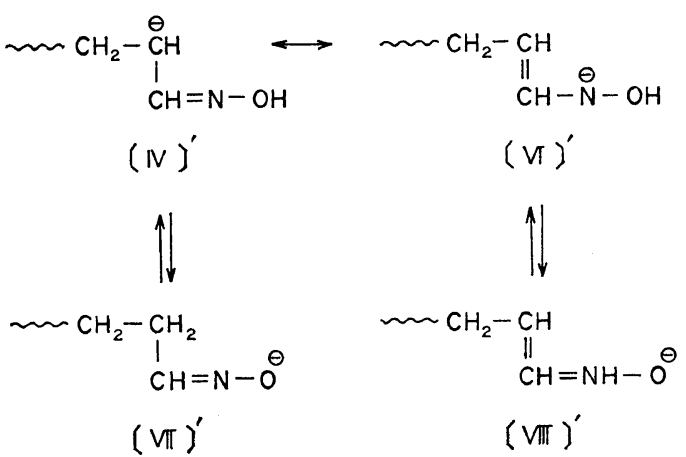

Figure 5. Resonance and equilibria for growing chain end. hindrance. Vinyl peaks at 1405, 990, and $925 \mathrm{~cm}^{-1}$ are seen in the infrared spectrum of PAOM, but they are very small compared with those in the case of AOM. These smaller peaks can be attributed to the vinyl group of the AOM monomer unit located at the chain end. Thus the carbon-carbon double bonds in PAOM should arise only from paths (C) and (E), and $12 \%$ of the structural units, mentioned above as unknown, seems to come about by path (D). The phenomenon of resonance and the migration of a proton at the end of the growing chain appear to govern the contents of the structural units in the resulting polymer. The growing-chain end has two resonance forms, $[\mathbf{I V}]^{\prime}$ and $[\mathbf{V I}]^{\prime}$, each of which is in equilibrium with its tautomeric anion as shown in Figure 5. The actual ratio of structure [IV] to [VII] in the resulting polymer seems to depend on the equilibrium concentrations of [IV] ${ }^{\prime}$ and $[\mathrm{VII}]^{\prime}$. If the same value of equilibrium constant is assumed for the interchange between $[\mathrm{VI}]^{\prime}$ and $[\mathrm{VIII}]^{\prime}$, the $\mathrm{C}=\mathrm{C}$ structural units, totaling $42 \%$ as mentioned above, should consist of the $33.3 \%$ [VI] and $8.7 \%$ [VIII] structures. From these data, the distribution of structural units for the PAOM with a $\bar{P}_{n}$ value of 30 is determined as

$$
\begin{aligned}
& \begin{array}{c}
\left.\mathrm{CH}_{2}=\mathrm{CH}-\mathrm{CH}=\mathrm{N}-\mathrm{O}+\mathrm{CH}_{2}-\underset{\mid}{\mathrm{CH}}\right)_{13.8}-\left(\mathrm{CH}_{2}-\mathrm{CH}_{2}-\mathrm{CH}=\mathrm{N}-\mathrm{O}\right)_{3.6}- \\
\mathrm{CH}=\mathrm{N}-\mathrm{OH}
\end{array}
\end{aligned}
$$

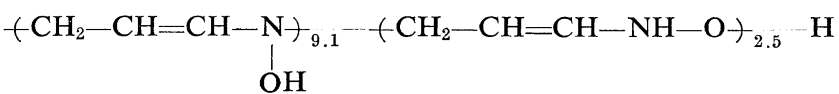



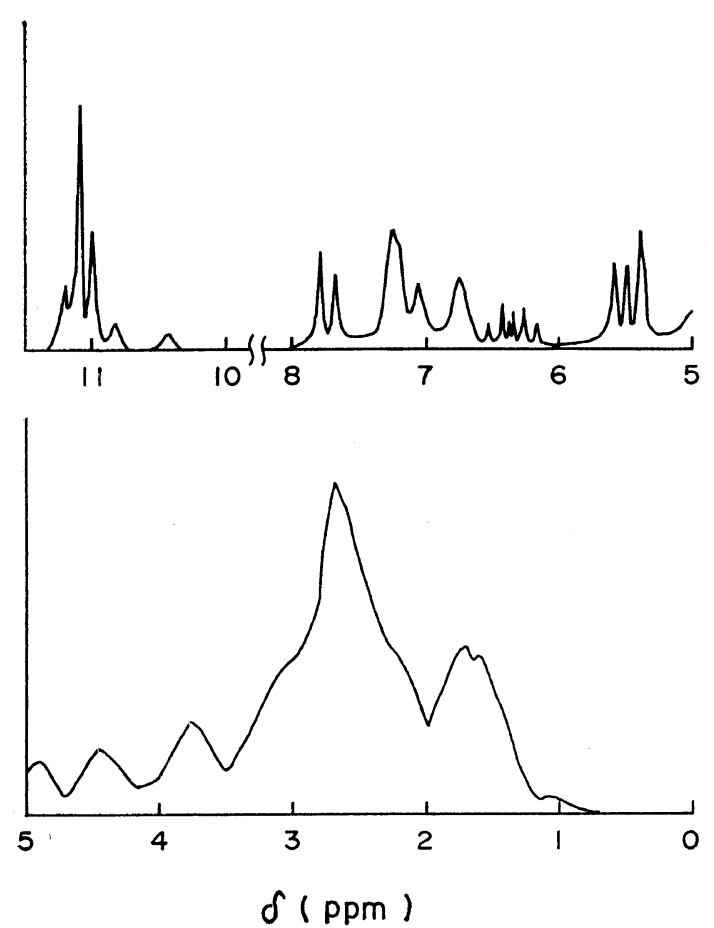

Figure 6. MNR spectrum of PAOM.

The data on both the hydrolysis and NMR spectroscopy of PAOM show that it contains $\mathrm{CH}_{2}=\mathrm{CH}-\mathrm{CH}=\mathrm{N}-\mathrm{O}-$ as its terminal unit. The hydrolysis gave AOM, which can not be produced from any of the above-described structural units other than the terminal one. As shown in Figure 6, the NMR spectrum has a multiplet at around $11 \mathrm{ppm}$, which becomes faint when heavy water is added. The multiplet seems to indicate the presence of $-\mathrm{NH}-$ as well as $\mathrm{OH}$ groups. The peaks at 7.71, 7.04, 6.40 , and $5.50 \mathrm{ppm}$ are assigned to the protons of the end group, $\mathrm{CH}_{2}=\mathrm{CH}-\mathrm{CH}=\mathrm{N}-.^{2}$ The other peaks are due perhaps to the backbone of the polymer, but the exact assignment is difficult because of the structural complexity.

\section{REFERENCES}

1. S. Masuda and T. Ota, Kobunshi Ronbunshu, 31, 61 (1974).

2. S. Masuda, H. Kihara, and T. Ota, Nippon Kagaku Kaishi (J. Chem. Soc. Jpn., J. Chem. Ind. Chem.), 1974, 608.

3. B. V. Ioffe and K. N. Zelenin, Izv. Vysshikh Uchebn. Zavedenii, Khim. i Khim. Tekhnol., 6, 78 (1963).

4. M. Fineman and S. D. Ross, J. Polym. Sci., 5, 259 (1950).

5. Y. Toi and Y. Hachihama, Kogyo Kagaku Zasshi (J. Chem. Soc. Jpn., Ind. Chem. Sect.), 64, 595 (1961).

6. D. D. Van Slyke, Ber., 43, 3170 (1910).

7. I. P. Losev and O. Ya Fedotova, "Praktikum po Khimii Vysokopolymernykh Soedinenii," Gosudarstvennoe Nauchno-Tekhnicheskoe Iedatelistvo Khimicheskoi Literatur, Japanese translation, Gihōdō, Tokyo, 1965, p 67.

8. W. Hückel, "Theoretische Grundlagen der Organischen Chemie," Akademische Verlagsgesellschaft, Japanese Translation, Shōkō Publishing Co., Tokyo, 1959, Vol. 2, p 547.

9. S. Califano and W. Luttke, Z. Phys. Chem., 5, 240 (1955).

10. D. S. Breslow, G. E. Hulse, and A. S. Matlack, J. Am. Chem. Soc., 79, 3760 (1957). 